\title{
Thermoplastic Composite Materials for the Aerospace Industry
}

ISSN: 2576-8840

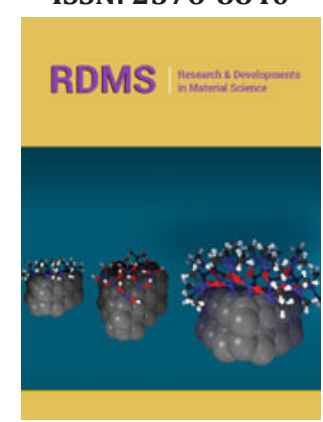

*Corresponding author: Fahrettin Ozturk, Department of Mechanical Engineering, Ankara Yildirim Beyazit University, Turkey

Submission: 侮July 01, 2021

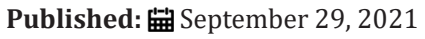

Volume 15 - Issue 5

How to cite this article: Oguzhan Bas, Elvan Ates, Fahrettin Ozturk. Thermoplastic Composite Materials for the Aerospace Industry. Res Dev Material Sci. 15(5). RDMS.000872. 2021. DOI: 10.31031/RDMS.2021.15.000872

Copyright@ Fahrettin Ozturk. This article is distributed under the terms of the Creative Commons Attribution 4.0 International License, which permits unrestricted use and redistribution provided that the original author and source are credited.

\author{
Oguzhan Bas ${ }^{1}$, Elvan Ates ${ }^{1,2}$ and Fahrettin Ozturk ${ }^{1,2 *}$ \\ ${ }^{1}$ Department of Mechanical Engineering, Ankara Yildirim Beyazit University, Turkey \\ ${ }^{2}$ Turkish Aerospace Industries Inc., Ankara, Turkey
}

\begin{abstract}
Composite materials combined with thermoset or thermoplastic resin with glass or carbon reinforcements are indispensable materials for structural parts used in the aerospace industry. Structural materials that have high strength/weight ratio together with low cost, and short processing time are preferred in aerospace. Considering these features, thermoplastic composite materials are excellent candidates for future aircraft materials due to their high strengths, design flexibility, and corrosion resistance. In this study, the advantages of composite materials in the aerospace industry are discussed and the manufacturing processes of thermoplastic composite materials are reviewed.
\end{abstract}

Keywords: Aerospace industry; Thermoplastic composite materials; Manufacturing and assembly process

\section{Introduction}

Technology, which is one of the most basic needs of humanity, has continued to develop since the industrial revolution with its undeniable reality. Along with new inventions based on the efficient use of energy, automotive and aerospace industries have become the building blocks of technology. The rapidly developing metal industry has brought the serial manufacturing capability to the industry. On the other hand, high-strength light alloy steels developed in the aerospace industry could not show the desired performance in terms of energy, material life, and design flexibility. Aerospace components, also known as structural materials, should have high stiffness, enhanced toughness, and machinability capabilities [1].

Composite materials that can contain these conditions are produced by combining at least two different macro-dimensional materials. Although materials cannot dissolve in each other, some interactions occur. Composite materials are preferred in the aerospace industry due to their lightness, production costs, and strength properties in structural components. The significant increase in the use of composite material ratios of aircraft produced in recent years is the biggest proof of this. Existing aircraft programs such as the Airbus A350 [2], Boeing B787 Dreamliner, or Bombardier C-Series CS-100 [3] demonstrate the evidence of this condition, with composite materials which is 50-53 percent of their overall structural weight.

In the defense and aerospace industry, the application of thermoplastic composite materials is becoming increasingly important. The first use of thermoplastics on airplane parts was on the landing gear and weapons bay doors of the US military's F-22 jet fighter (1980) [4]. The main wing leading edges of the Airbus A380 superjumbo passenger aircraft and the A340 500/600-series airliners that preceded it, as well as the rudder and elevators of the Gulfstream Aerospace G650, are currently flying thermoplastic composite flight-critical components [5]. For many years, based on the importance of thermoplastic composites, projects such as Thermoplastic Affordable Primary Aircraft Structure (TAPAS) has been 
carried out by major aerospace companies, based on the principles of lower fuel consumption and costs of the aerospace industry [5].

When compared to ordinary metallic materials, composite materials stand out because of their excellent specific strength value [1]. Thus, aircrafts can be produced with low-cost, highperformance materials suitable for manufacturing, and achieve the desired features such as corrosion resistance and design flexibility in terms of increased flight efficiency and technical possibilities. Based on aerodynamic calculations, these advanced materials, which significantly reduce aircraft acceleration response and fuel consumption, are the materials of the future for the aerospace industry [6]. Ultimate targets in the industry are summarized in Figure 1.

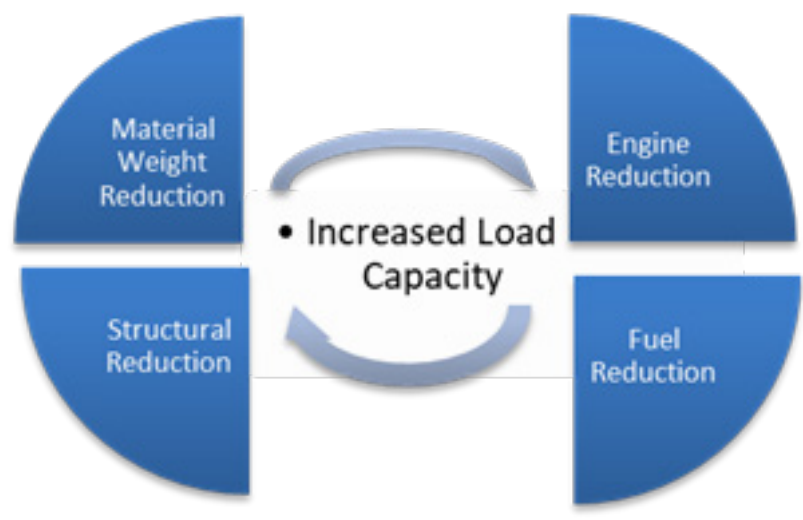

Figure 1: Goals of the aerospace industry.

Polymer-based composite materials come to the fore in terms of production flexibility. In particular, thermoplastic composite materials have a highly viscous structure at glass transition temperatures due to their re-formability and are compatible with thermoforming methods.

\section{Composite Materials}

Composite material, which are obtained by combining the superior properties of two or more materials are used to improve properties such as corrosion resistance, thermal resistance and low weight [7]. Composites structures are considerably more complex than any other structure since composite materials are comprised of two constituents, reinforcement and matrix, which preserve their self-properties during the combination process. Reinforcing fibers contribute to determining the mechanical properties of composite materials via the orientation and length of the fibers. Mechanical characterization of the composite structure reveals that fibers are anisotropic materials, which change the properties of materials with directions.

\section{Reinforcement}

The classification of fibers is typically formed by the reinforcement constituent as materials. The fiber, held together with the matrix resin, provides high tensile strength, and improves the properties of the final part such as strength and stiffness. These properties are the most desired properties in many areas since they reduce the weight of the composite materials. Fiber volume, architecture, and orientation are essential points in determining the mechanical properties of stiffness and strength [8]. Fiber architecture, i.e. the arrangement of fibers in a composite, influences not only the properties and performance of the composite but also its processing. In the industry, frequently used fibers are E-glass and carbon fibers. Glass fibers are much cheaper and less rigid than carbon fibers [9].

\section{Matrices}

The matrix forms the main structure of the composite structure. It plays an important role in transferring the loads between fibers to hold the fibers in place via its cohesive and adhesive properties. It also protects the equipment from mechanical degradation and environmental hazards. The resin provides a critical inelastic reaction, reducing stress concentrations and redistributing internal stresses from the reinforcements [10]. Fiber reinforced plastics use two types of matrix materials, thermosets and thermoplastics. Thermoplastic materials are preferred because of their sustainability features, ease of production, re-formability [11].

\section{Environmental effects on composite materials}

Composite materials have been used in a variety of fields in aerospace engineering such as turbine blades, exterior surfaces, and hypersonic vehicles because of their superior flexural stiffness, high light-weight properties, and thermal protection abilities [1215]. Mechanical properties of composite materials are affected by extremely low and high environmental temperatures. Composites show different behaviors according to type of reinforcements \& resins, different geometrical structures, stitched and unstitched forms, and type of matrices like carbon-matrices /carbide-matrices under extremely environmental conditions.

In extremely low temperatures $-70{ }^{\circ} \mathrm{C}$ to $23{ }^{\circ} \mathrm{C}$, Compression After Impact (CAI) strength and compressive stiffness of carbon fiber composites with PVC-sandwich structures severely decreased and it was performed with helping of change impact energies [12]. A wide variety of failure mechanisms occur on composite structures such as delamination and separation of interfacial bonds in arctic condition [16]. Moreover, the stitched polyimide laminates and unstitched CFRP woven laminates impacted in arctic conditions $\left(-70{ }^{\circ} \mathrm{C}\right)$, matrix damage of both is significantly greater with comparing to room temperature. The unstitched CFRP woven laminates is delicate. According to the crack damage propagation, stitched polyimide composites have good damage performance [15].

In high temperatures above $90{ }^{\circ} \mathrm{C}$, the mechanical properties such as stiffness of composite materials decreased as temperature increased. Reducing of the stiffness and mechanical strength are depending on to softening properties of polymer matrix. Between $60-90{ }^{\circ} \mathrm{C}$ temperatures, plastic flow of polymer is followed up and above $90{ }^{\circ} \mathrm{C}$, inter-laminar micro cracking failure mechanisms are observed. In extremely high temperatures above $1600{ }^{\circ} \mathrm{C}$, it is a critical value for aerospace industry such as rocket motor nozzle 
temperature reaches to $3000{ }^{\circ} \mathrm{C}$ according to the high-pressure gas, and high-velocity grains [14]. A few studies are done to generate new thermal protection materials which have good oxidation resistance and thermal shock abilities. Carbon fiber reinforced ultra-high temperature ceramic composites C-SiC-UHTC matrix are adequate for using on hypersonic vehicles, which show high strength and fracture toughness, and superb thermal shock resistance [14].

Table 1: Thermoplastic resin materials used in aerospace industry [18].

\begin{tabular}{|c|c|c|c|c|}
\hline & PEEK & PEI & PPS & PEKK \\
\hline Used in aviation & 1980 & 1990 & 1990 & 2005 \\
\hline Polymer structure & Crystal & Amorphous & Crystal & Crystal \\
\hline Mechanical Properties & + & + & + & ++ \\
\hline Melting temperature & 343 & 310 & 280 & 331 \\
\hline $\begin{array}{c}\text { Process temperature } \\
\text { Glass transition } \\
\text { temperature }\end{array}$ & $370-400$ & 315 & 330 & 380 \\
\hline $\begin{array}{c}\text { Chemical resistance } \\
\text { List of Advantages } 0<-<+<++\end{array}$ & 210 & 90 & 162 \\
\hline
\end{tabular}

\section{Thermoplastic composites materials}

Thermoplastic composites have become more competitive when compared to thermoset polymers due to their matrix structures consisting of high-performance polymers and engineering polymers. The thermoplastic polymer is a material that can be heatsoftened, melted, and reshaped as many times as desired. They contain extremely strong bonds within chain molecules [17]. Most common thermoplastic resin materials are summarized in Table 1; [18].

\section{Manufacturing process of thermoplastic composite material}
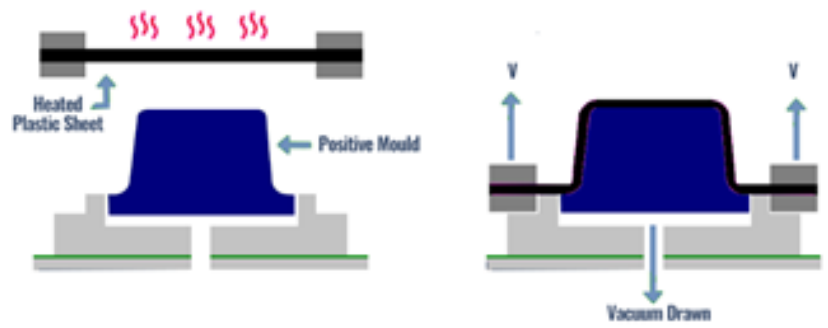

Figure 2: Thermoforming process [1].

The fact that thermoplastic materials can be stored at room temperature and have an unlimited shelf life saves waste and allows for more flexible manufacturing processes. Recyclable applications of thermoplastic composite materials are also supported in terms of European Union environmental sustainability standards [19]. Another production advantage of thermoplastic materials is their re-formability, thus enabling the correction of production tolerance errors. The latest manufacturing developments have improved the thermoplastic material production cycle and made the material more affordable, especially when the total cost of production is considered. Advances have affected every aspect of thermoplastic composite production, including prepreg (resinimpregnated fabric) production, design and part forming [20]. The thermoforming process is a rapid production method for thermoplastic composite materials. In this method, the twodimensional laminate structure, which has specified lay-up angles, is exposed to heat at the glass transition temperature level [21]. Considering the rheological conditions, the viscous composite material is transformed into a three-dimensional final structure with the help of the heat treatment provided by a press. The most critical feature in this process is the time elapsed between the first moment of contact of the material and mold and the moment the pressure is applied. The geometry of the molding tool used can be changed because of the complexity of the parts [22]. Schematics of the thermoforming process is illustrated in Figure 2.

\section{Assembly process of thermoplastic composite materials}

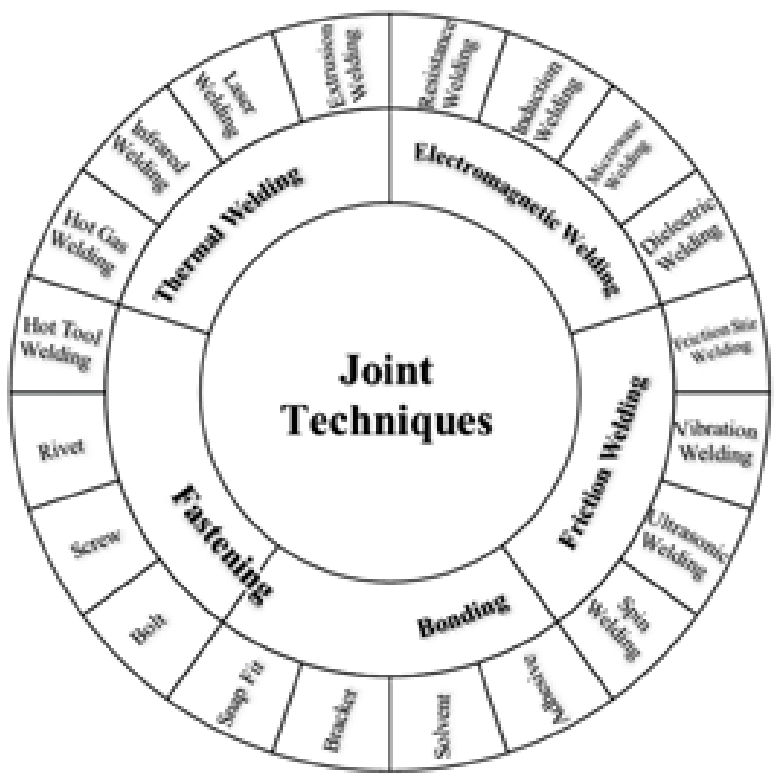

Figure 3: Joining techniques of composite materials [24].

The combination and assembly processes of composite materials are as important as the manufacturing processes. Drilling operations performed during conventional material assembly processes (screws, rivets, etc.) cause delamination in composite materials. Due to the negative effects of the mentioned mechanical joining methods on the material, new joining processes are being developed in composite material technology [23]. Different joining techniques are seen in Figure 3; [24]. Strength and tenacity analysis, optimization of laying angles, the combinability of materials are current research topics. Welding is considered as the most advantageous process among the new joining processes.

Welding in composites is basically the joining of plastic material with different process steps, as it is in metals. However, welding in composites cannot be applied to all plastic types, it can only be applied to thermoplastics [25]. This is due to the fact that the chemical structure of thermoset composite materials changes after heat treatment [26]. Thermoplastic composites have the ability to 
be melted, reshaped, and consolidated up to a certain stage due to the chemical bonds they contain. Therefore, the recycling rate is very high when compared to other types of plastic, and it has a direct positive effect on the economy in terms of consumption [19]. Resin flow is an important parameter in thermoplastic composites because of the weld quality that characterizes the strength of the part [27].

\section{Conclusion}

The importance and competence of composite materials in the aerospace industry were discussed. Nowadays, tremendous number of efforts is being made to use thermoplastic composite materials for primary aircraft structures. The suitability and weldability of thermoplastic composite materials for aircraft structures provide significant weight reduction. Thus, it is assessed that thermoplastic composite materials, which are intended to replace materials such as metal and steel, can make significant contributions to aerospace companies in terms of cost in the long term, with their properties such as recyclability and storability at room conditions. Another challenge could be on the repair technology since damaged areas can easily be repaired.

\section{References}

1. Barile $M$, Lecce L, Iannone $M$, Pappadà $S$, Roberti $P(2020)$ Thermoplastic composites for aerospace applications. In: Pantelakis S, Tserpes K (Eds.), Revolutionizing Aircraft Materials and Processes. Springer, Germany.

2. Marsh G (2007) Airbus takes on Boeing with reinforced plastic. Reinf Plast 51(11): 26-29.

3. Marsh G (2013) Bombardier throws down the gauntlet with CSeries airliner. Reinf Plast 55(6): 22-26.

4. Pantelakis S, Tserpes K (Eds.), Revolutionizing Aircraft Materials and Processes.

5. Veijer J (2015) Analytical model of a mold dependent production line: Applied to future thermoplastic skin panel production for Gulfstream G650 tail wings.

6. Kedward KT (2000) Generic approaches and issues for structural composite design and application. Comprehensive Composite Materials.

7. Leterrier Y (2000) 2.33-life cycle engineering of composites. Comprehensive Composite Materials 2: 1073-1102.

8. Mallick PK (1997) Composites engineering handbook. CRC Press, USA.

9. Nayak Ramesh (2018) Evaluation of mechanical properties of glass fibre and carbon fibre reinforced polymer composite. 8: 66-74.

10. Steven L Donaldson, Daniel B Miracle (2004) ASM Handbook. Composites.
11. Reis JP, de Moura M, Samborski S (2020) Thermoplastic composites and their promising applications in joining and repair composites structures: A Review. Materials (Basel), 13(24): 5832.

12. Elamin M, Li B, Tan KT (2021) Compression after impact performance of carbon-fiber foam-core sandwich composites in low temperature arctic conditions. Composite Structures 261: 113568.

13. Tan KT, Elamin M, Li B (2017) Impact performance and damage behavior of composite sandwich structures in arctic condition. Proceedings of the American Society for Composites-Thirty-second Technical Conference.

14. Tang S, Hu C (2017) Design, preparation and properties of carbon fiber reinforced ultra-high temperature ceramic composites for aerospace applications: A review. Journal of Materials Science \& Technology 33(2): 117-130.

15. Elamin M, Li B, Tan KT (2018) Impact performance of stitched and unstitched composites in extreme low temperature arctic conditions. Journal of Dynamic Behavior of Materials 4(3): 317-327.

16. Elamin M, Li B, Tan KT (2018) Impact damage of composite sandwich structures in arctic condition. Composite Structures 192: 422-433.

17. Mallick PK. Fiber reinforced composites materials, manufacturing, and design.

18. Özel D, Temiz AS (2018) An overview of thermoplastic composites from the world of aviation. pp. 1-19.

19. Krauklis AE, Karl CW, Gagani AI, Jørgensen JK (2021) Composite material recycling technology-state-of-the-art and sustainable development for the 2020s. J Compos Sci 5: 28.

20. Stiller H (1999) Material intensity of advanced composite materials. P. 90.

21. Mantell S, Springer G (1991) Journal of Composite Materials. (20 th $e d n)$, SAGE, Stanford, USA, pp. 2348-2377.

22. Brassard D, Dube M, Tavares JR (2019) Resistance welding of thermoplastic composites with a nanocomposite heating element. Composites Part B: Engineering 165: 779-784.

23. Swift KG, Booker JD (2013) Manufacturing Process Selection Handbook.

24. Kumar S, Medhi T, Roy BS (2019) Friction stir welding of thermoplastic composites. Springer Nature Singapore Pte Ltd., Agartala, India.

25.Villegas IF, Moser L, Yousefpour A, Bersee H, Mitschang P (2013) Process and performance evaluation of ultrasonic, induction and resistance welding of advanced thermoplastic composites. Journal of Thermoplastic Composite Materials, pp. 1007-1024.

26. Dolter T (2009) Basic concepts of chemistry, ( $8^{\text {th }}$ edn), John Wiley \& Sons, USA.

27. Shi H, Villegas IF, Bersee HEN (2016) Analysis of void formation in thermoplastic composites during resistance welding. Journal of Thermoplastic Composite Materials, pp. 1-21. 